\title{
AN UNUSUAL CUT WRIST: A CASE STUDY AND A REVIEW OF LITERATURE
}

\author{
Dina Galal Ibrahim a \\ a Forensic Medicine and Clinical Toxicology Department, Cairo University, \\ Egypt.
}

Corresponding author: Dina Galal Ibrahim

e-mail:dina.galal@kasralainy.edu.eg

Date of submission: 6 May 2020

Revised at: 4 June 2020

Accepted at: 6 June 2020

\begin{abstract}
Background: According to World Health Organization statistics, the annual suicidal death rate is about one million people worldwide (mean mortality rate: 16/100.000). In some countries, suicide is the second leading cause of death in the 1024-year age group. Wrist cutting is sometimes practiced with the goal of self-harm rather than being a suicidal attempt. However, if the bleeding is copious or allowed to continue unchecked, cardiac arrhythmia which is followed by severe hypovolemia, shock, circulatory collapse or cardiac arrest, and death may ensue. Another aim from self- cutting could be wound fabrication to mimic physical assault. In the current study, the updated knowledge concerning self-inflicted injuries including medicolegal, theoretical, and methodological approaches to assess such incidents, is discussed. Methods: a rare case of unusual, ambiguous cut - wrist will be presented. It is a case of an Asian, female, domestic worker who was claimed to commit suicide at her sponsor's house by deliberately cutting her left wrist. In a bloody scene, the deceased was found with a completely severed left wrist leading to a complete left- hand amputation. The right hand with a small bloody sharp knife was found behind the body. Results and conclusion: after a detailed examination of the death scene and full autopsy, the debate appeared. Both homicidal and suicidal scenarios were possible. However, no evidence was found to confirm the homicidal accusation. Consequently, the case was reported as a possible suicide with no previously reported similar cases in the literature.
\end{abstract}

Keywords: Homicide, suicide, cut-wrist, amputation, self-harm.

\section{INTRODUCTION}

Upper limb injuries, especially the hand, are crucial in forensic medicine. Self-inflicted injuries, with a little reference to suicide attempt-related upper extremity injuries, represent the majority of these injuries. However, these injuries are not as common as other trauma types. The increasing rate of suicide attempts is progressing to become an important social problem due to its reasons and consequences (Esren et al., 2015).

On the other hand, Amararatne and Vidanapathirana(2017) demonstrated that in some cases, ascertaining the death manner by the forensic pathologist is an intractable procedure. This usually occurs when attempts are made by the criminals to conceal homicides as suicides. An unusual 
death manner, especially when it is accompanied by a little crime scene evidence, will be an addition to the complicity to solve the puzzle (Brunel et al., 2010).

Self-cutting injuries have a low mortality rate; however, they have a special clinical significance since they lead to a destructive disability and the possibility of recurrent attempts. Many suicidal methods aim to self-mutilation during attacks of rapid mood swing which are usually followed by cardiac arrhythmia, severe hypovolemic shock, circulatory collapse or cardiac arrest, and death (Richard et al., 1972).

Unusual self-inflicted violence takes place in many cases with psychological disturbances background such as Schizophrenia. No or little pain recorded in survivors during the act (Lizardo et al., 2015). Cases of Body Integrity Identity Disorder (BIID) are also involved in self-harm categories. It describes in the extreme uncommon phenomenon of an individual eagerness to amputate one (or more) healthy limb or who desire a paralysis. Some distort themselves; others request a surgical amputation or spinal cord transection. From the forensic point of view, sometimes self-inflicted harm could be misdiagnosed as suicidal or homicidal events (Sabine, 2009).

A case presented to the forensic medicine department in the Ministry of Interior in the State of Kuwait was one of the most confusing cases managed, as after the investigations of the crime scene team and the investigator's opinion gathered with the forensic report, the picture of being a selfinduced injury was raised.

\section{Case Presentation}

A 33-year old female Asian domestic worker was found dead in the employer house, in a small storage room next to the kitchen. Her left hand was nowhere to be seen. She was lying in a bloody scene and after the removal of her body, her left hand together with a small house-hold knife were found below her body (fig. 1,2). Blood was seen scattered on one side of the kitchen floor, cupboards, and the nearby basin and tap (fig. 3). The blood was copious, mostly below the deceased. Death scene examination showed no suspicious disorder in the kitchen, the storage room, or a trace of any other person(s). Only blood traces and fingerprints, which refer to the deceased, were found on the small knife. Finger and footprints together with the blood spatter found in the crime scene were examined and they were all related to the deceased only without any other foreign print or DNA traces. Testifying the witnesses (the employer family and another worker) revealed that she joined their house 4 weeks before the incident with no suspected abnormal behaviour, no medical history of any mental illnesses as well as the fact that she was not on regular medications.

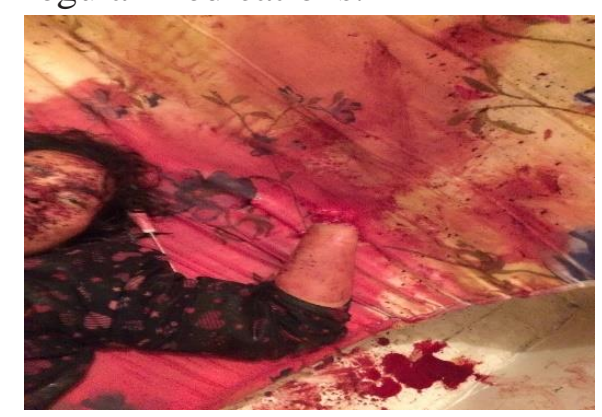

Figure 1: the body of the deceased and the knife with blood splash on the face and surroundings. 


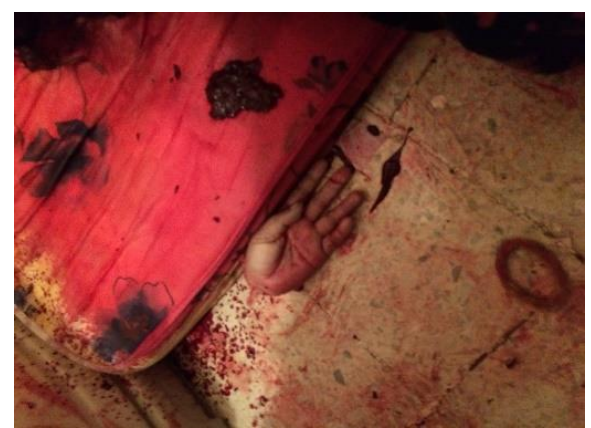

Figure 2: the separated left hand was found below the body after removal.

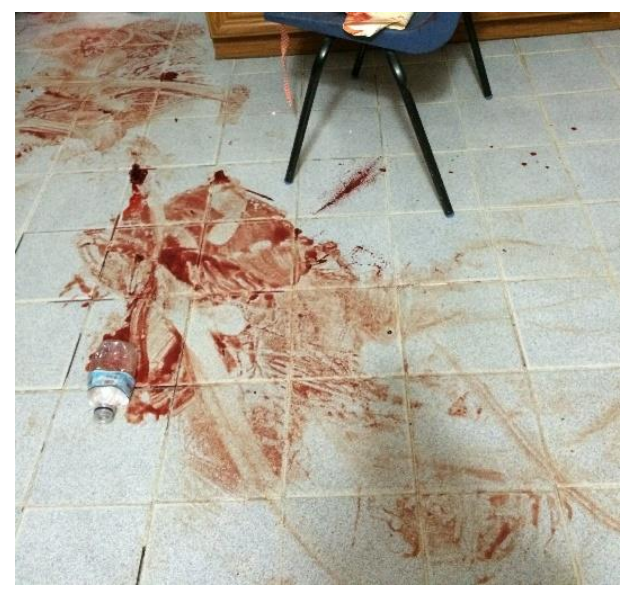

Figure 3: the blood on the kitchen floor.

\section{At autopsy:}

External body examination revealed intact blood-soaked uniform and underclothes, free of any suspicious cuts, tears, or signs. Examining the blouse, the left sleeve was seen folded almost until below the elbow. Dried blood was found covering right and left hands together with the exposed arm and face. The body displayed a complete rigor mortis state. The whole body was in extreme pallor, accompanied by pale hypostases on the back with no signs of putrefaction. The separated hand was related to the amputation site and was found to be the exact match with no missing tissue after skin traction was done to the left forearm(fig.4).
Sharp-edged irregular cuts were found at the base of the separated left hand and the opposing distal end of the corresponding forearm, including the skin and the soft tissues traversing the joint (fig. 5,6). The cartilaginous cover of the bony surfaces at the separated wrist joint in both detached parts was found to be intact except for 2 small superficial scratches in the hand-related cartilaginous surface. The left forearm was free of any cuts or bruises, with retracted skin and soft tissues at the distal end upwards. Both palms were free of any injuries or defensive wounds.

A full autopsy and pathological examination were conducted. Radiological screening displayed a whole-body skeleton free from fractures or foreign bodies. The cause of death was declared to be due to hypovolemic shock resulting from copious external bleeding from the severed major blood vessels traversing the wrist joint. Cut nails and swabs from both palms were taken for DNA analysis which revealed the absence of foreign DNA. Vaginal and anal swabs were negative for semen. Toxicology analysis of blood, urine, stomach contents and organs was negative for any drugs or suspicious material. Preliminary pregnancy screening test in urine was negative. Neither Ethyl nor methyl alcohol was found in the blood samples taken from the deceased. 


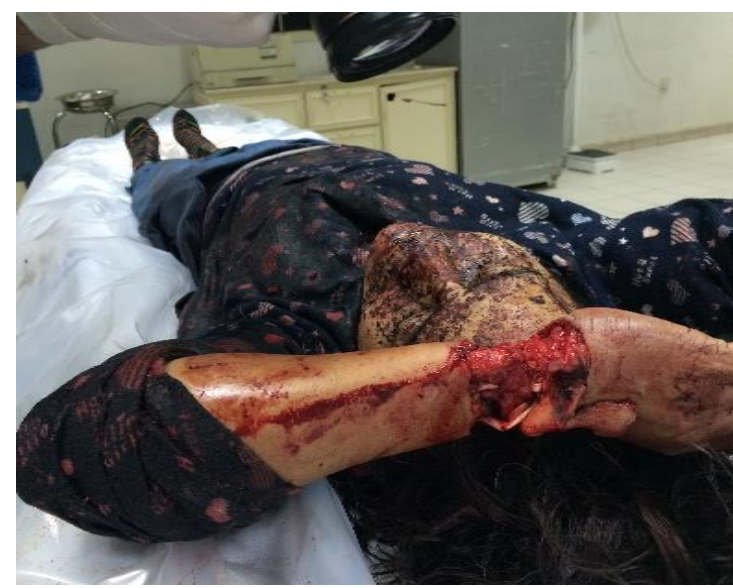

Figure 4: the left hand and forearm were put together with no missing tissue with previously displaced sleeve.

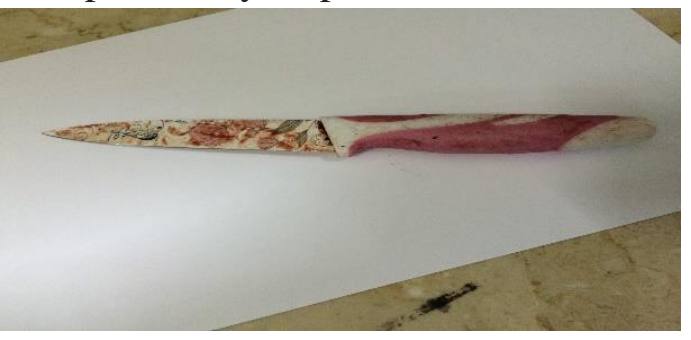

Figure 4: the knife.

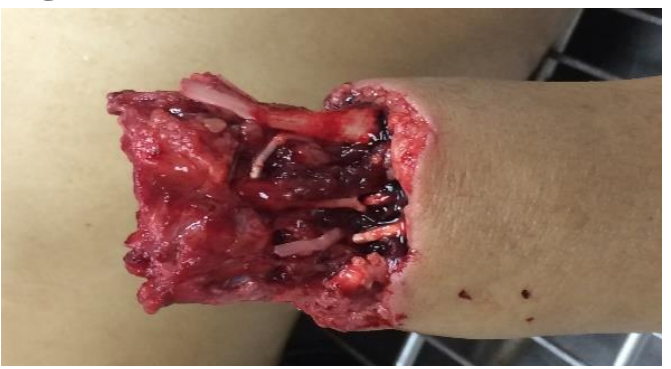

Figure 5: the lower end of left forarm.

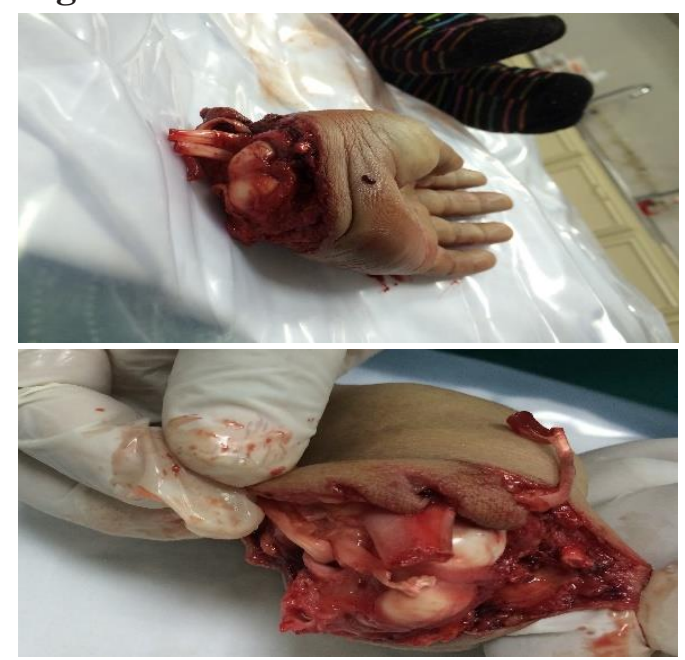

Figure 6: the left separated hand with sharp irregular cuts on its proximal end.
Homicidal and self-induced injury were both potentially probable and were the suggested scenarios in this case. As regards the homicidal possibility, the points of concern were the intact external and inner clothes, the left sleeve was pulled up till the left elbow, while the right sleeve was covering the right forearm until the right wrist, the absence of other suspicious inflicted injuries in the body along with the absence of defensive wounds. Besides, finger and foot-prints, in the scene, were only related to the deceased, apart from the absence of foreign DNA traces (not related to the deceased) in the crime scene and the body as well. After the finalization of the forensic, crime scene and police investigations reports, the suspicion of the self-inflicted scenario was raised.

\section{DISCUSSION}

Self-inflicted aggression falls under many psychiatric, mental, and neurological disorders. A suicidal aim is not always present in self-inflicted injury cases, which could be only differentiated before death occurs. After death, things become more complicated, and the role of forensic pathologists alone turns out to be very difficult (Ohshima and Condo, 1997). The medical and social history which would be declared from the relatives and those who are close to the deceased before death, together with the medical records and data, if available, could be of great guidance. On the other hand, irrelevant data could worsen the situation and make the mission more difficult (Fujioka et al., 2012). 
Wrist cutting is among the commonest self-inflicted injuries with suicidal intentions, while others are practicing the wrist cut for self-harm. The severity of wrist cutting ranges from a superficial skin cut to a severe injury of major blood vessels, nerves, and tendons. Cases of wrist cutting are usually saved before sever insult occurs, while deaths occur as a sequence of cardiac arrhythmia followed by severe hypovolemic shock, circulatory collapse followed by cardiac arrest. The left wrist is the commonest to be injured by the right-handed, which is usually uncovered with clothes (Esren et al., 2015).

Self-mutilation is an individual who intentionally damages part of his or her own body - apparently - without a conscious intent to die; many of them deny awareness of the act. It is common among psychiatric patients, particularly those with borderline personality disorder or schizophrenia. It is deliberate self-harm (cutting, nonsuicidal self- injury). These types of injuries were reported under a wide range of specialties and different psychiatric disorders which may be buried within the broader categories of "self-injury" or "suicide" or even in the "homicidal" range (Fujioka et al., 2012). Cutting is the most commonly used method, targeting fingers, hands, wrists, and thighs, although any part of the body may be considered. Severity could end with permanent disfigurement or death. Studies showed that little or no pain is felt during the act which is explained mainly through sever distraction from emotional pain, problems, self-punishment, and selfpurification (Hamid et al.,2015).

Harsh cases of self-destruction, sometimes, can be interpreted through several mental disorders. Body Integrity Identity Disorder (BIID) is an extremely rare brain disorder leading to a disruption of the body image with a lack of autonomy where one desires the amputation or paralysis of a healthy $\operatorname{limb}(\mathrm{s})$ as if it does not belong to them (Sarah and Erich, 2014). Paraphilia, Factitious Disability Disorder, Body Dysmorphic Disorder (BDD), Obsessive-Compulsive Disorder (OCD), and Dissociative Identity Disorder (DID) can be other explanations. However, in some neurological studies, it is considered a peripheral disturbance which is a congenital mismatch between the physical body and the body image (Steffen and Manfred, 2006 ).

Alien Hand Syndrome, is similar to BIID. This syndrome usually occurs after a stroke, bleeding, or a tumor in the brain. The patients cannot identify the (left) hand as their own one which sometimes acts against their intentions. The ethical dilemma regarding medical amputation, as one of the suggested management procedures to help those patients, has been raised. Other selfamputation procedures recorded were; dry ice amputation, pellet-gun, selfinduced infections, self-injection aiming necrosis, railway, electric saw or chopper (Sacco and Calabrese, 2010).

Difficulties in cases diagnosis are usually referred to as multiple factors. Absence of medical records and history 
for the patient (especially in case of death), different aims of self-induced injuries (harm, BIID, suicide), dereliction in researchers in the area of self -mutilation and unusual manners of self -aggression scarcely reported and updated in different medical branches. Apart from that, self -inflicted injuries will never be fully understood or explained, thus continuous studies and updates together with interchanging the data between different medical branches are mandated, putting in mind the overlapping in management of such cases (Karger et al., 2000). On the other hand, teamwork between forensic, crime scene and laboratory is crucial in the management of intricate criminal cases. Furthermore, Medical records are decisive in such cases especially those endangering their, or others, life (Mościcki, 2001).

\section{CONCLUSION}

The suicidal act represents a behaviour that could never be completely comprehended or demonstrated. The reason for this is being a reflection, in itself, to conduct that is contrary to human nature and non-instinctive behaviour. Additionally, humans are the only species that perpetrate suicide and has auto-aggressive behaviour. Consequently, one can speculate to the fact that the human psyche represents an important, if not the only, operator involved in the self-harm act. Moreover, it is generally believed that the more unusual the technique and the means used, the more serious the psychiatric disorder may be. Considering the remarkable method used in the case presented above, it could be assumed that the hypothesis that the suicidal act can almost always be considered as a manifestation expressing an implied (latent or manifest) mental imbalance or a psychiatric pathology. The study of the circumstances, a careful screening of the scene of death, a full autopsy, and a methodical toxicology analysis are necessary to demonstrate the exact mode of death in such cases.

\section{CONFLICT OF INTEREST}

There are not any financial, personal, or professional interests that could be construed to have influenced the work.

\section{Funding Disclosure: Not applicable}

\section{REFERENCES}

Amararatne RS1 and Vidanapathirana M(2017): A Crime Scene Fabricated as Suicide. Journal of Clinical and Diagnostic Research. 11(2). doi: 10.7860/JCDR/2017 123672.9441.

Brunel C, Fermanian C, Durigon M and de la GrandmaisonGL(2010):

Homicidal and suicidal sharp force fatalities: autopsy parameters in relation to the manner of death. Forensic Sci Int. 198: 150-154.

Ersen B, Kahveci R, Saki MC, Tunali $O$ and Aksu I (2015): Analysis of 41 suicide attempts by wrist cutting: A retrospective analysis. Eur J Trauma Emerg Surg. 43(1). doi: 10.1007/s00068-015-0599-4. 
Fujioka M, Murakami C, Masuda K and Doi H(2012): Evaluation of superficial and deep self-inflicted wrist and forearm lacerations. $\mathbf{J}$ Hand Surg. 37:1054-8.

Hamid R, Nikoletta A, Petrou M and Aamer S(2015): Case Report Self-Amputation in Two NonPsychotic Patients. Iran J Psychiatry Behav. 9(3): e231.

Karger $\mathbf{B}$, Niemeyer $\mathbf{J}$, and Brinkmann B(2000): Suicides by sharp force: typical and atypical features. Int J Legal Med.113: 259-262.

Lizardo C, Ronald V, Katia C, Carla CV and Patricia NM(2015): Severe Burns and Amputation of Both Arms in the First Psychotic Episode of a Schizophrenic Patient. Hindawi Publishing Corporation. 2015:405713-5 pages. doi: 10.1155/2015/405713.

Mościcki EK(2001): Epidemiology of completed and attempted suicide: toward a framework for prevention. Clinical Neuroscience Research.1(5): 310-323.

Ohshima $T$ and Kondo $T$ (1997): Eight cases of suicide by selfcutting or -stabbing: consideration from medico-legal viewpoints of differentiation between suicide and homicide. J Clin Forensic Med. 4(3): 127-132.

Richard J R, Carl R, Rita W and Edmund K(1972): Wrist-Cutting Syndrome: The Meaning of a Gesture. American Journal of Psychiatry. 128(11):1363-1368.

Sabine M (2009): Body Integrity Identity Disorder (BIID)-Is the
Amputation of Healthy Limbs Ethically Justified?. The American Journal of Bioethics. 9(1): 36-43.

Sacco $L$ and Calabrese $P(2010)$ : Alien hand syndrome: a neurological disorder of will. Schweiz Arch Neurol Psychiatr. 161(2):60-3.

Sarah N and Erich K (2014): Body integrity identity disorder (BIID): How satisfied are successful wannabes. Psychology and Behavioural Science. 3(6): 222232

Steffen $H$ and Manfred K (2006): Self-Inflicted Injuries: A Forensic Medical Perspective. Dtsch Arztebl. 103(40): A 2627-33. 


\section{الملخص العربي \\ قطع رسغ غير اعتيادي: دراسة حالة و مراجعة

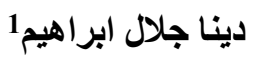 \\ قسم الطب الثرعى و السموم الاكلينيكيه, كلية الطب جامعة القاهرة 1}

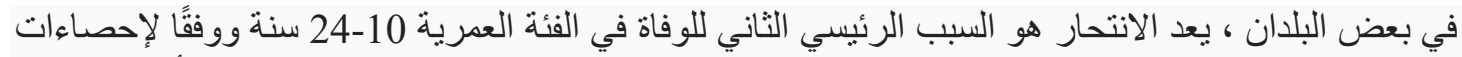

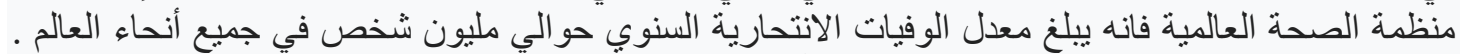

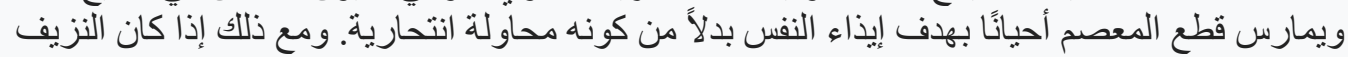

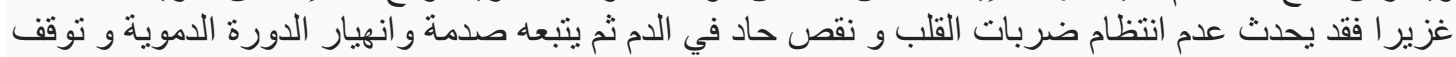

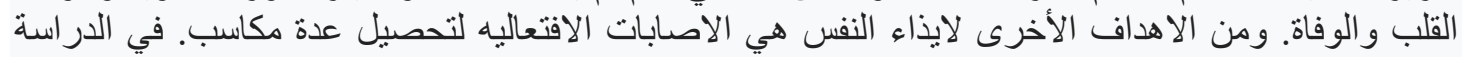

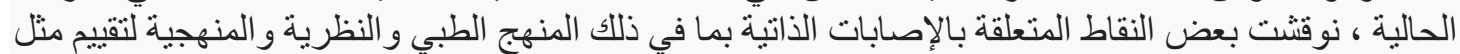

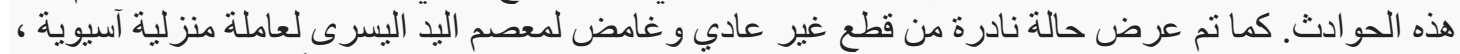

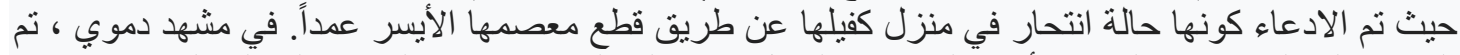

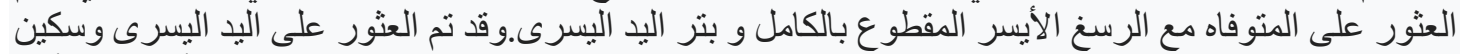

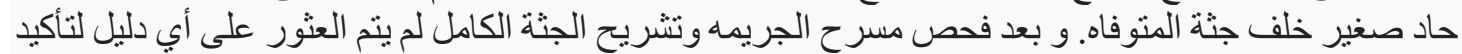

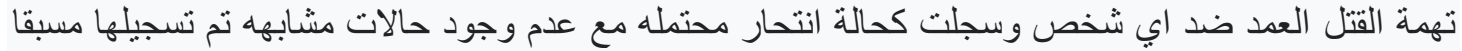

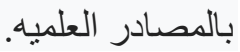

